Pre-publication version (Oct 13, 2009; errors corrected Mar 7, 2011). To appear in NLLT(DOI 10.1007/s11049-011-9123-7).

\title{
[+wh] complementizers drive phonological phrasing in Fukuoka Japanese
}

\author{
Jennifer L. Smith \\ University of North Carolina, Chapel Hill
}

\begin{abstract}
Evidence from the intonation of wh questions in the Fukuoka dialect of Japanese is used to explore a recent proposal by Richards that the syntax-prosody interface includes a requirement for wh elements and their associated complementizers to be contained in the same phonological phrase. An examination of multiple wh questions and nested wh questions determines that this phrasing requirement originates with the complementizer, not with the wh element.
\end{abstract}

\section{Prosodic structure and the syntax-phonology interface}

Syntactic information can affect phonology, as seen when differences in syntactic structure correlate with differences in the applicability or domain of phonological processes (Selkirk 1981, 1986; Kaisse 1985; Nespor and Vogel 1986; Chen 1987; Truckenbrodt 1999). However, the kinds of syntactic information that have been empirically demonstrated to have phonological consequences are quite limited. Thus, two fundamental goals of research in the syntax-phonology interface are first, to determine which aspects of syntactic structure do have relevance for the phonology, and second, to develop a linguistic model that accounts for the restricted nature of this interface.

One perspective on the second question, stated explicitly by Inkelas $(1989$, p. 9$)$ as the Indirect Reference Hypothesis, holds that phonological rules may not refer to syntactic constituency. Instead, syntactic constituency influences prosodic structure - in particular, the formation of phonological phrases - and it is prosodic structure to which apparently syntax-sensitive phonological processes actually refer. There are multiple approaches to modeling just how syntactic constituency influences prosodic structure, including the Edge Alignment model (Selkirk 1986; Chen 1987), according to which an individual language sets parameters to match left or right edges of syntactic XPs with left or right edges of phonological phrases; and the Mutiple Spell-Out model, according to which syntactic Spell-Out domains are mapped either directly (Ishihara 2007) or indirectly (Kratzer and Selkirk 2007) onto phonological phrases. For concreteness, a version of the Edge Alignment model is used here, but this choice is not crucial for the argument at hand; the Multiple Spell-Out approach is further discussed in $\S 5$.

The main focus of this paper is a subpart of the first question: Which aspects of syntactic structure have relevance for the phonology? Specifically, it is shown here, based on the prosodic structure of wh questions in the Fukuoka dialect of Japanese, that the inventory of syntactic factors affecting phonological phrase formation must be expanded beyond the widely acknowledged factors in (1).

(1) Syntactic influences on the phonological phrase (PhP)

a. $\quad$ Syntactic constituency: Edges of maximal projections (XPs) may map to edges of PhPs (Selkirk 1986; Chen 1987), or Spell-Out domains may determine the extent of PhPs (Ishihara 2007; Kratzer and Selkirk 2007)

b. Wrap-XP: A (lexical) XP may be required to be contained within some $\mathrm{PhP}$ (Truckenbrodt 1999) 
c. Focus: Focus marking may override syntactic constituency and Wrap-XP effects, affecting the placement of PhP edges (Pierrehumbert and Beckman 1988; Nagahara 1994;

Truckenbrodt 1999; but see Ishihara 2007 for an alternative view)

Crucially, in Fukuoka, the span from a wh element to its associated complementizer (C) must be realized as a single, default-accented phonological phrase (Kubo 1989 et seq.), but the factors listed in (1) are insufficient to account for this phenomenon. The Fukuoka pattern somewhat resembles a Wrap effect (1b) in that one single prosodic phrase must contain both the wh element and its associated C. However, the original Wrap-XP formalism as proposed by Truckenbrodt (1999) applies specifically to syntactic constituents, whereas in Fukuoka wh constructions, it is not a lexical XP, or indeed necessarily any syntactic constituent at all (see (8) below), that is being 'wrapped.' Instead, the domain of the Wrap effect appears to be the wh feature chain. Furthermore, unlike the superficially similar case of Tokyo Japanese, Fukuoka wh prosody cannot be reduced to a combination of Spell-Out effects (1a) and focus phonology (1c) (see $\S 5$ for discussion). Thus, the Fukuoka pattern shows that, in addition to syntactic constituency $(1 \mathrm{a}, \mathrm{b})$ and focus (1c), wh features are also relevant for phonological phrase formation.

A proposal by Richards (2006) treats the Fukuoka phenomenon as part of a more general pattern involving wh features and phonological phrases. ${ }^{1}$ Richards states the following principle, which may be called the wh/C phrasing condition, and demonstrates its application in several languages.

wh/C phrasing condition (Richards 2006, p. 10)

Given a wh phrase $\alpha$ and a complementizer $C$ where $\alpha$ takes scope, $\alpha$ and $C$ must be separated by as few minor phrase boundaries as possible, for some level of minor phrasing.

As Richards shows, the effects of the wh/C phrasing condition vary by language. In some languages, $\alpha$ moves overtly to be closer to $C$, as in English. In other languages, $\alpha$ remains in situ but a large phonological phrase is formed that includes both $\alpha$ and $C$, and this is precisely what is observed in Fukuoka Japanese.

The wh/C phrasing condition is an intriguing proposal, since it draws a connection between two formerly unrelated patterns: the syntactic parameter that determines whether a language will make use of overt or covert wh movement, and the existence of wh-specific phonological phrasing effects as seen in Fukuoka. Still, it is not yet clear why this phrasing condition exists, or whether it might be reducible to more basic principles.

This paper makes an initial contribution toward a more fundamental understanding of the wh/C phrasing condition. Specifically, evidence from Fukuoka intonational structure shows that it is a requirement of the complementizer $\mathrm{C}$, not the wh element $\alpha$, that drives this phrasing condition. First, $\S 2$ provides background on pitch accent and simple wh questions in Fukuoka Japanese. The next two

1 Many researchers recognize two levels of phonological phrasing, the major phrase and the minor phrase (see §2.1). Richards (2006) states his phrasing condition in terms of the minor phrase, which also turns out to be the level of phrasing that is relevant for Fukuoka wh prosody, so it is the minor phrase that will be the focus of discussion here. Other researchers (e.g., Selkirk and Tateishi 1991; Truckenbrodt 1999; Kratzer and Selkirk 2007) argue that the major phrase plays a role at the syntax-phonology interface. Recently, Ito and Mester (2007) have proposed that 'major phrase' and 'minor phrase' are merely the same prosodic category - the phonological phrase- used in a recursive structure. 
sections present patterns of greater complexity that reveal the crucial role of the complementizer in wh prosody: multiple wh questions $(\S 3)$ and nested wh questions $(\S 4)$. Finally, $\S 5$ confirms that a wh-specific phrasing requirement truly is needed for Fukuoka, because approaches developed for Tokyo that rely on focus phonology and multiple Spell-Out are insufficient for this dialect.

\section{Fukuoka Japanese pitch accent and simple wh questions}

This section presents an overview of pitch accents, phrasing, and intonation in Fukuoka Japanese, highlighting the differences between wh constructions and other structures. First, as a basis for comparison, the more extensively studied Tokyo Japanese accent and intonational system is summarized (§2.1). Then, the Fukuoka system is introduced (\$2.2), with special attention to the prosody of wh questions.

\subsection{Japanese accent and intonation basics: The case of Tokyo}

The following is a basic summary of the Tokyo Japanese accent and intonation patterns, on which the subsequent discussion of the Fukuoka dialect is based. Foundational English-language descriptive and theoretical works concerning pitch accents, phrasing, and intonation in Tokyo include McCawley (1968), Poser (1984), Pierrehumbert and Beckman (1988), Selkirk and Tateishi (1991), and Venditti (1997, 2005).

A word in Tokyo Japanese may be accented or unaccented. Accented words bear a pitch accent, which is phonetically realized as an abrupt pitch fall from high tone $(\mathrm{H})$ to low tone $(\mathrm{L})$. The Tokyo pitch accent is represented phonologically by Pierrehumbert and Beckman (1988) as /HL/, or more explicitly in later formalizations (e.g., Venditti 1997, 2005) as $/ \mathrm{H}^{*}+\mathrm{L} /$, with a high tone $\left(\mathrm{H}^{*}\right)$ that is associated to the mora phonologically designated as bearing the accent, plus a low tone $(+\mathrm{L})$ that is generally realized on a closely following mora.

Other aspects of the pitch contour of a Tokyo utterance have to do with phrase-level intonational tones. At least two levels of phonological phrasing, which is to say two prosodic constituents above the level of the phonological word, have been proposed for Tokyo. The larger phonological phrase is called the major phrase (MaP) by McCawley (1968) (also known as the intermediate phrase in Pierrehumbert and Beckman 1988 and as the intonation phrase in Venditti 1997, 2005). The smaller phonological phrase, which is of more immediate concern here, is McCawley's (1968) minor phrase (MiP; called the accentual phrase by Pierrehumbert and Beckman as well as Venditti).

According to the analysis in Pierrehumbert and Beckman (1988), each minor phrase is associated with a phrasal H tone, represented /H-/ (following Venditti 1997, 2005), which associates near its left edge, and also with a final low boundary tone, represented /L\%/. The /L\%/ tone associates to the first mora of the following minor phrase, if any, except that when the following phrase starts with an accented syllable or a syllable with two sonorant moras, the $/ \mathrm{L} \% /$ tone remains floating and does not surface phonetically. A post-pausal minor phrase is also preceded by a low boundary tone, represented $/ \% \mathrm{~L} / \mathrm{by}$ Venditti (1997, 2005), subject to the same linking conditions as the /L\%/ tone. Thus, the presence of a low tone on the phrase-initial mora followed by a higher tone on the second mora, a pattern traditionally known as Initial Lowering, is diagnostic of the left edge of a minor phrase (although, because the low tone 
will not associate in minor phrases that have initial accent or an initial syllable with two sonorant moras, Initial Lowering is not observed in these environments).

Phrasal tones are assigned to every minor phrase, although they may be deleted or phonetically undershot when many tones are crowded together on few syllables. However, the $/ \mathrm{H}^{*}+\mathrm{L} / \mathrm{pitch}$ accent tones are present only when a word in the phrase is accented. Consequently, the overall intonational contour differs between phrases that contain accented words and those that contain only unaccented words.

As an illustration of these patterns, consider an unaccented word like momoiro 'peach color, pink' uttered as a phrase in isolation. This phrase has an initial /\%L/ boundary tone, a phrasal / $\mathrm{H}-/$ tone, no pitch accent, and a final floating /L\%/ tone. This produces a pitch contour that starts low, rises relatively quickly, then continues as a flat or slightly decreasing high tone. ${ }^{2}$

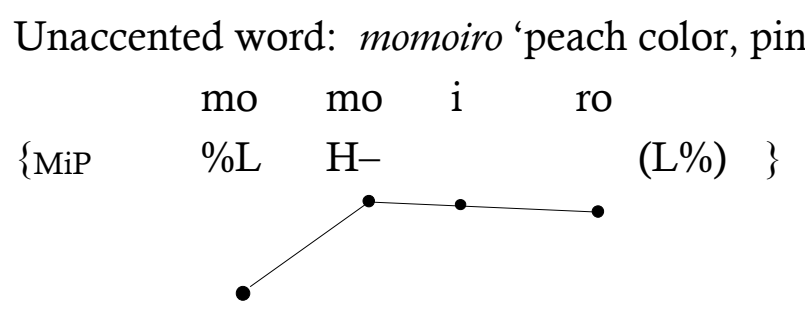

An accented word like murásaki 'purple', again uttered as a phrase in isolation, likewise has an initial /\%L/ boundary tone, a phrasal / $\mathrm{H}-/$ tone, and a final / $\mathrm{L} \% /$ tone, but there is also a $/ \mathrm{H}^{*}+\mathrm{L} / \mathrm{pitch}$ accent, the $\mathrm{H}^{*}$ of which is associated with the accented syllable [rá] (and which is not possible to distinguish in the pitch contour from the phrasal $/ \mathrm{H}-/$ tone in this case). For this form, the pitch contour starts low, rises relatively quickly, falls abruptly for the pitch accent, and continues as a flat low tone.

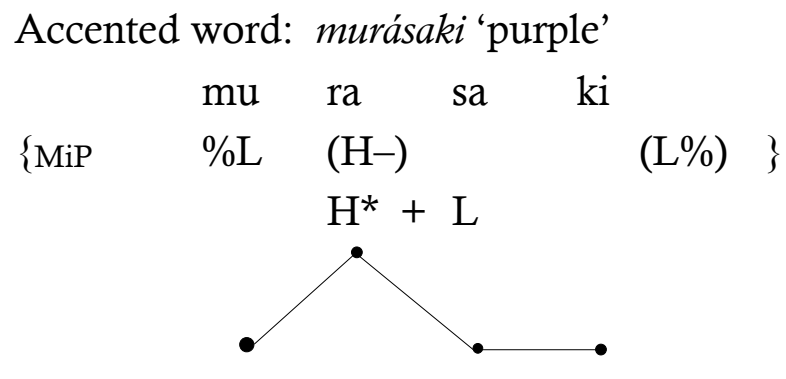

Thus, in Tokyo Japanese, a minor phrase containing only unaccented words differs from a minor phrase containing an accented word in that the latter contains an abrupt pitch fall, but the former does not.

\subsection{Accent, intonation, and simple wh questions in Fukuoka}

The term 'Fukuoka Japanese' refers to the dialect of Japanese spoken in and surrounding the city of Fukuoka in Fukuoka prefecture, northwestern Kyushu. The city can be broadly divided into two areas,

2 Schematic pitch contours are provided here for the purposes of illustration; each dot represents one mora. For pitch tracks produced from recordings of Tokyo utterances, see, e.g., Poser (1984), Pierrehumbert and Beckman (1988), or Venditti (1997, 2005). 
Hakata and Fukuoka; there are phonological and morphosyntactic differences between Hakata and Fukuoka dialects, but they generally pattern together with respect to wh-related intonational phenomena (Kubo 1989, p. 1). The basic description of Fukuoka intonation, and most of the Fukuoka data discussed here, are taken from detailed impressionistic work by Hayata (1985) and especially Kubo (1989 et seq.).

Although the Fukuoka and Tokyo dialects are neither closely related nor geographically contiguous, and individual morphemes may have different word-level accent patterns in the two dialects, the overall Fukuoka pitch-accent and intonational system greatly resembles that of Tokyo (Hayata 1985; Kubo 1989 et seq.). Many aspects of the phonological analysis of Tokyo laid out in $\$ 2.1$ can therefore be applied to this dialect as well.

Fukuoka morphemes may be accented or unaccented, and accent is realized as a pitch fall that can be phonologically represented as the familiar $/ \mathrm{H}^{*}+\mathrm{L} /$ melody. A minor phrase begins with a lower pitch and climbs quickly to a higher pitch, and if there are no accented words to contribute an abrupt pitch fall, the minor phrase shows a gently decreasing flat high tone; again as in Tokyo, this can be analyzed in terms of a phrasal / $\mathrm{H}-/$ tone that associates near the left edge of the phrase, and a preceding $\% \mathrm{~L}$ (or L\%) boundary tone that is realized as a phrase-initial low pitch when the conditions for its association are met.

An example of a minor phrase containing an accented word can be seen in the yes/no question in (5), which is an utterance produced by a female speaker of Fukuoka Japanese as part of a randomized list of wh questions, yes/no questions, and noun phrases (Smith, unpublished data). The second syllable of monó 'thing' is accented, so this syllable bears a high tone and there is a pitch fall immediately afterward.

(5) Example of a minor phrase with an accented word: Accent realized as pitch fall

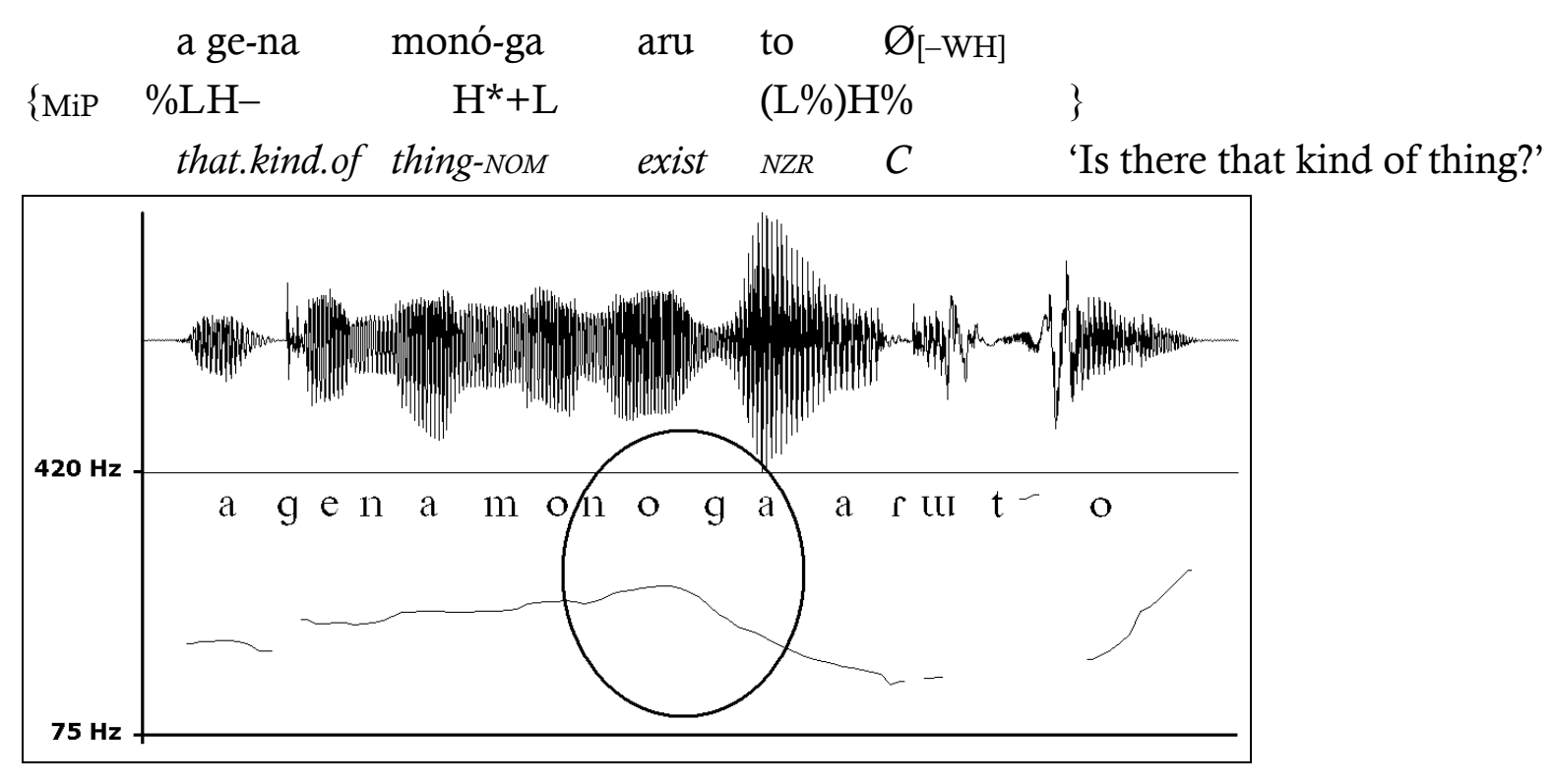

The utterance-final rise in (5) can be analyzed phonologically as a / $\mathrm{H} \%$ / tone that is a boundary pitch movement (BPM) indicating a matrix question (see Venditti 2005 for an overview of analogous BPMs in Tokyo Japanese). The (L\%) in parentheses represents a minor-phrase boundary tone that is not linked to any mora; it is included in the representation (rather than assumed to be deleted or never assigned) on analogy with the analysis of Tokyo minor-phrase /L\%/ tones in Venditti (1997, 2005), but nothing crucial hinges on this representational assumption. Here and in subsequent examples, acute accent (ó) marks a 
pitch accent that is phonetically realized. In wh questions, bold underline indicates wh elements and associated complementizers. ${ }^{3}$

The example in (5) demonstrates that the Fukuoka accent and intonation system in non-wh constructions greatly resembles the Tokyo system. Fukuoka wh questions, however, show a different intonational contour from other constructions (Hayata 1985; Kubo 1989 et seq.). ${ }^{4}$ An example of Fukuoka wh prosody can be seen in (6), which forms a minimal contrast with the yes/no question in (5), and was produced by the same speaker. The two utterances are composed of identical lexical items, except that where (5) has age-na 'that kind of', (6) has the wh element doge-na 'what kind of'. In (6), crucially, the underlying accent on monó 'thing' does not surface; there is no pitch fall between the syllables [no] and [ga]. Instead, the high flat pitch typical of an unaccented minor phrase is observed, with the utterance-final rising tone that signals a matrix question.

(6) Example of a wh question: No pitch fall for underlyingly accented monó

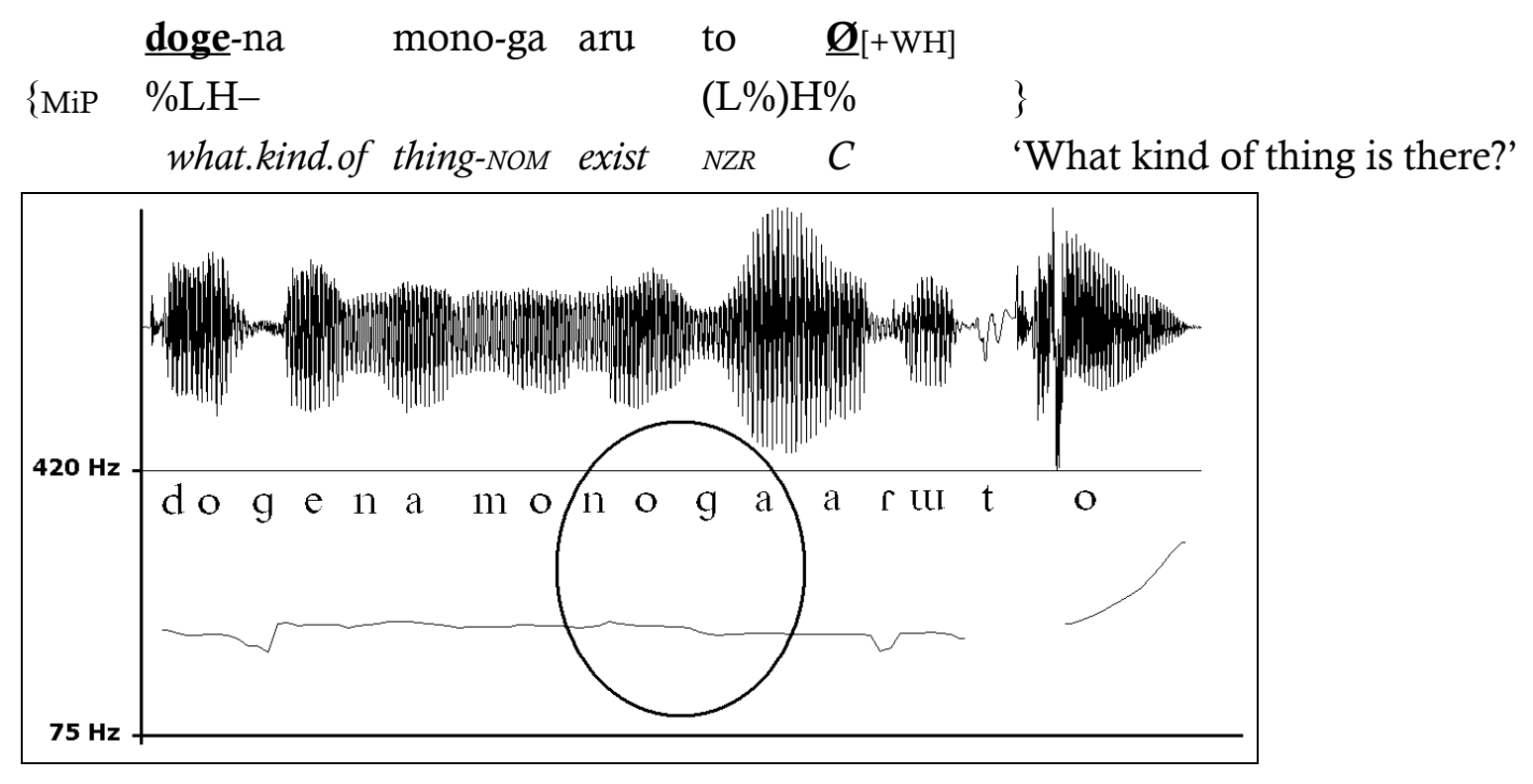

Kubo's most recent phonological generalizations concerning Fukuoka wh prosody (Kubo 2001, 2005, 2010) can be summarized as follows: All material between a wh element, here doge-na, and its associated complementizer, here the null [ $+w h]$ complementizer in sentence-final position, is encompassed in a single minor phrase, in which all pitch accents that would be expected in a non-wh construction are deleted. This single minor phrase then remains unaccented if the [+wh] complementizer is both null and sentence-final. Otherwise, it receives a default accent, which surfaces in antepenultimate or penultimate position based on phonological (or possibly morphological) factors; see Kubo (2001, 2010) for two different analyses of the location of the default accent. ${ }^{5}$

3 Abbreviations used in glosses are as follows: NOM nominative, ACC accusative, GEN genitive, LOC locative, TOP topic, STAT stative, NEG negative, COP Copula, QUOT quotative particle, and NZR nominalizer.

4 Fukuoka wh intonation also differs from Tokyo wh intonation; see §5.

5 The default accent behavior of wh-related minor phrases is complex and deserves further study. That the inserted accent is indeed a default, and not a lexical accent contributed by overt complementizers, is demonstrated by Kubo (1990a, p. 109). That the environment where default accent insertion is blocked necessarily involves a null complementizer (which is only 
The size and extent of the wh-related minor phrase depends on which complementizer is associated with the wh element, that is, on the scope of the wh element. ${ }^{6}$ The following example, from Kubo (1989), contrasts a wh question that has matrix scope (7b) with a wh question that has scope only over the embedded complementizer (7c), showing that the special wh prosody ends at the appropriate complementizer (recall that a default accent appears when the complementizer is overt). A non-wh utterance is provided as well (7a), to demonstrate the expected phrasing and pitch accents in the absence of any wh-specific minor phrase. (As above, phrase tones /L\%/ and /H-/ are shown in parentheses when they are not phonetically realized.)

(7) Correlation between wh prosody and wh scope (Kubo 1989, p. 1-3) ${ }^{7}$

a. Yes/no question: Ordinary pitch accents and phrasing appear

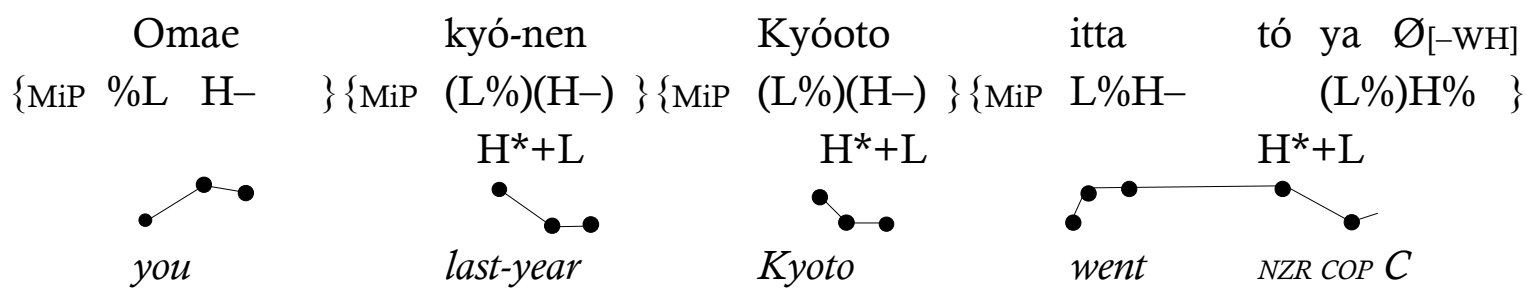

'Did you go to Kyoto last year?'

b. Matrix wh question: wh MiP to end of matrix clause; no pitch accents surface

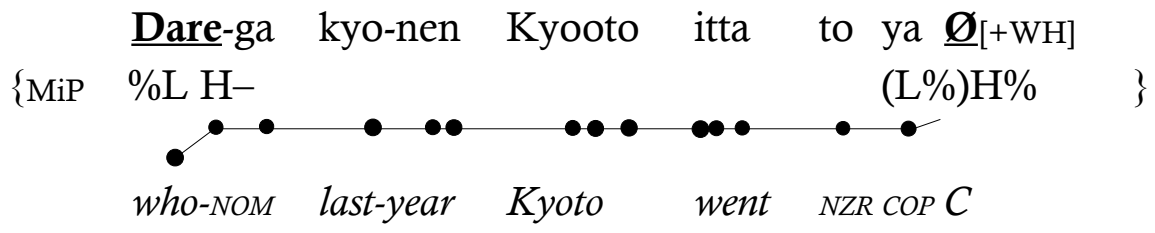

'Who went to Kyoto last year?'

c. Embedded wh question:

wh MiP ends at $k a$; no pitch accents surface in that span except penultimate default

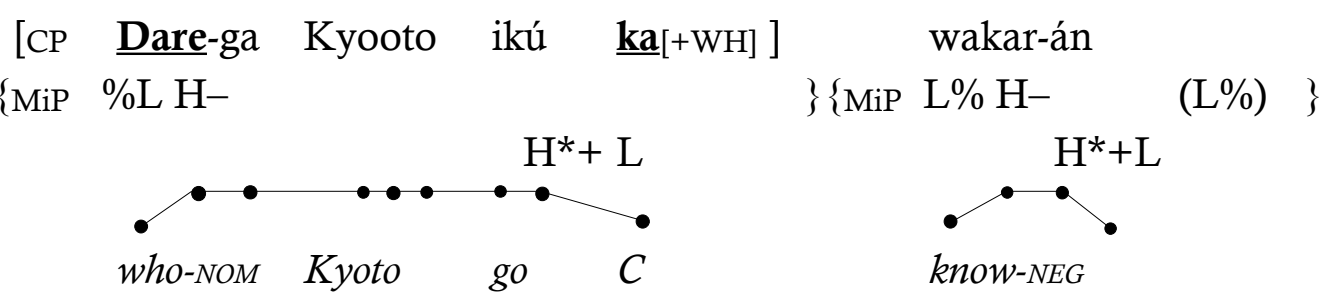

'(I) don't know who's going to Kyoto.'

possible in a matrix clause), and not just any matrix wh question, is demonstrated by Kubo (2001, p. 28; 2010, p. 55). As for why there is no accent insertion when the $[+w h]$ complementizer is null and matrix-clause-final, Kubo (1992, p. 271; 2010, §4.2) examines other circumstances in which a default, predictable accent that is generally mandatory is suppressed in the environment of a nearby sentence-final rising intonational tone; he tentatively suggests that some shared factor involving modality may be at work.

6 There is a well-known correlation between prosody and wh scope in Tokyo Japanese as well, but there are important differences between Tokyo and Fukuoka wh prosody. See $\S 5$ for discussion.

7 Kubo (1989) does not explicitly distinguish the null complementizer $\varnothing_{[ \pm \mathrm{WH}]}$ from the copula $y a$ in this example or from the quotative tte seen in subsequent examples, but I follow Kubo $(1990 \mathrm{a}, \mathrm{b})$ in making these distinctions. 
Following the detailed impressionistic discussion and transcriptions of Kubo (1989 et seq.), an absence of Initial Lowering is shown in (7b) in the locations corresponding to those in which it appears (at itta) or potentially appears (at kyonen and at Kyooto, once the lexical pitch accents on these words have been suppressed) in (7a). The absence of Initial Lowering - and the infelicity of the emphatic particle kusa, which must be followed by a phrase break (Kubo 1989, pp. 75-76) - between a wh element and its associated complementizer are interpreted, following Kubo, as demonstrating the lack of any minorphrase boundaries within this span.

Although the right edge of the wh-related minor phrase is determined by a [+wh] complementizer, thereby coinciding with the right edge of a $\mathrm{CP}$, the left edge is determined by the location of the wh element, wherever it is in the clause. This means that the wh-related minor phrase is not necessarily a syntactic constituent, as shown by the slightly abbreviated tree structure in (8) for an example from Hayata (1985, p. 27); curly brackets $(\{\ldots\})$ indicate the boundaries of this minor phrase.

The wh-related minor phrase need not be a syntactic constituent

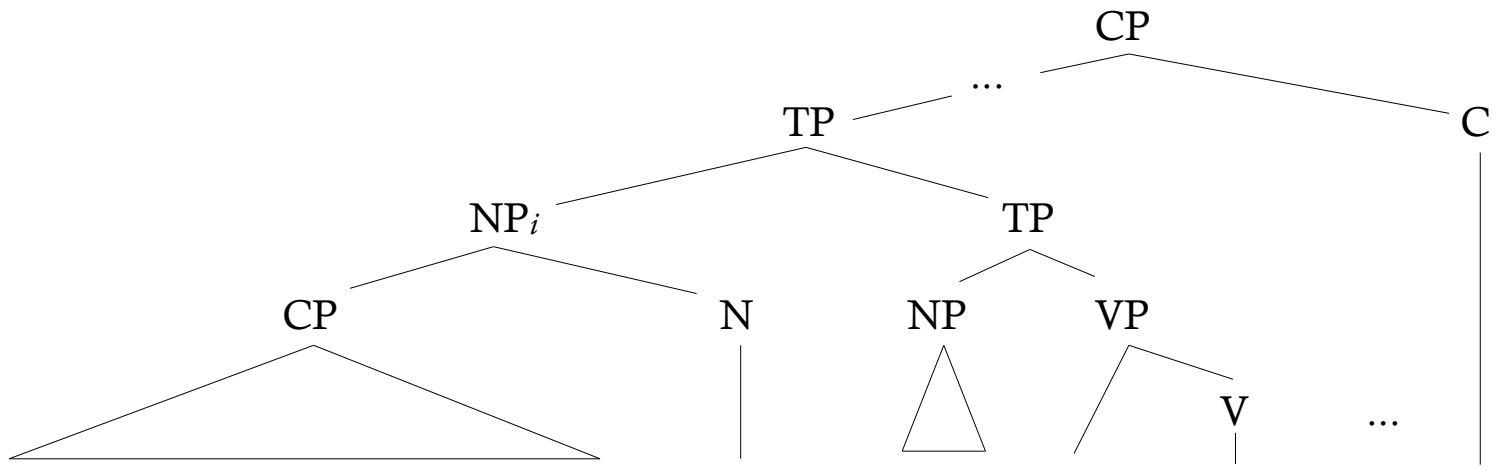

[ [CP ore-ga $\{\underline{\text { itu }} \text { Kyooto kara katte-kita ] yatuhasi-o ] }]_{i}$ omae-wa $t_{i}$ kutte-simoota to ya $\left.\left.\underline{\emptyset}_{[+\mathrm{WH}}\right]^{\wedge}\right\}$

[ [ I-NOM when Kyoto from buy-brought] yatsuhashi-ACC] ] you-TOP ti ate.up NZR COP $C$ 'Which yatsuhashi did you eat, identified by when I brought them back from Kyoto?' (lit., ( ${ }^{*}$ Eng) 'When $j$ did you eat the yatsuhashi [CP that I brought back from Kyoto $\left.t_{j}\right]$ ?')

Here, the wh-related minor phrase starts in the middle of the relative clause ore-ga itu Kyooto kara katte-kita, which modifies the head yatuhasi of the preposed object NP, and continues to the end of the matrix clause; clearly, there is no syntactic constituent that corresponds to this string of terminal elements.

The Fukuoka Japanese examples presented in this section have demonstrated the intonational characteristics of the wh-related minor phrase and have shown that its extent depends on the scope of the wh element. Thus far, the data have not determined whether the requirement that the wh element and its associated complementizer be phrased together is driven by the $\mathrm{C}$ or by the wh element; either option is a logical possibility. These two possibilities may be formalized as Optimality-Theoretic constraints, as in (9) (although the fundamental question of which element is ultimately responsible for the wh/C phrasing condition is not dependent on the choice of analytical framework). 
(9) Two logically possible constraints behind the wh/C phrasing condition

a. WRAP-C Every $\mathrm{C}_{[+\mathrm{WH}]}$ must be in the same phrase as some associated wh element

b. WRAP-WH Every wh element must be in the same phrase as some associated $\left.\mathrm{C}_{[}+\mathrm{WH}\right]$

(WRAP constraints are an extension of Truckenbrodt 1999)

Examples with multiple complementizers and/or multiple wh elements clarify that it is in fact WRAP-C, and not WrAP-WH, that is active in Fukuoka Japanese; in other words, that it is the complementizer that drives the wh/C phrasing condition. Such examples are the topic of the following two sections.

\section{Multiple wh questions}

Multiple wh questions in Fukuoka show that requirements originating with the wh element itself make little or no contribution to the wh/C phrasing condition.

A multiple wh question ('Who bought what?') has two wh elements associated with the same complementizer. In Fukuoka, a wh-specific minor phrase is initiated at each wh element, as indicated in (10) ${ }^{8}$ Crucially, structures of this type require a phrase break, signaled as usual by a phrase-initial low tone, at the left edge of the second wh element. Kubo $(1989$, p. 3) explicitly reports that this example is ungrammatical without the phrase break at nan-nin.

$$
\begin{aligned}
& \text { Multiple wh questions: }\left[\mathrm{CP} \ldots \mathrm{wh}_{1} \ldots \mathrm{wh}_{1} \ldots \mathrm{C}_{1}\right] \text { (Kubo 1989, p. 3) } \\
& \{\text { MiP doko1-no daigaku-no gakusei-ga }\} \quad\left\{\text { MiP nan1-nin kita tte } \underline{\varnothing}_{[+\mathrm{WH}] 1^{\wedge}}\right. \text { \} } \\
& \text { where-GEN university-GEN student-NOM how.many.people came QUOT } C
\end{aligned}
$$

'How many students came from which university, reportedly?'

Example (10) shows that WRAP-WH is not ranked high in Fukuoka Japanese, since this structure includes one wh element (doko) that is not phrased together with its associated complementizer. What

8 Evidence that a wh-specific minor phrase is initiated even at the first wh element is provided by Kubo (1990a, p. 108), who gives the minimal pair in (i)-(ii). These two sentences differ only in whether the adjunct kyónen 'last year' is part of the matrix clause or part of the embedded clause. When kyónen is part of the matrix clause (i), its underlying pitch accent does not surface, which shows that it must be included in a wh-specific minor phrase-namely, one initiated by dare.

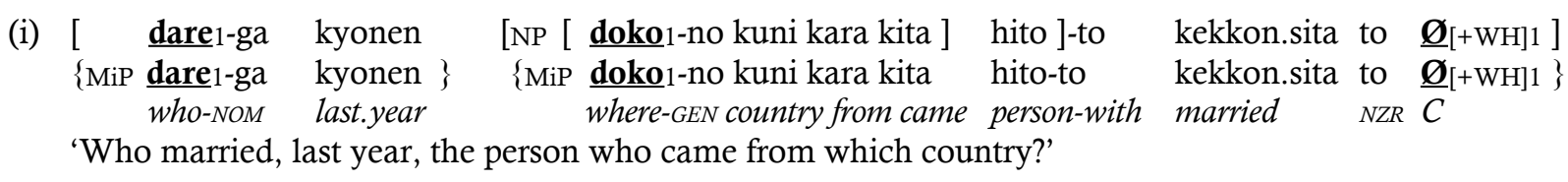

The example in (ii), where kyónen is the first word in the embedded clause, illustrates a further point about multiple wh questions: Because the accent on kyónen surfaces this time, we know there must be a phrase break at the left edge of the embedded clause as well as at the second wh element, doko.

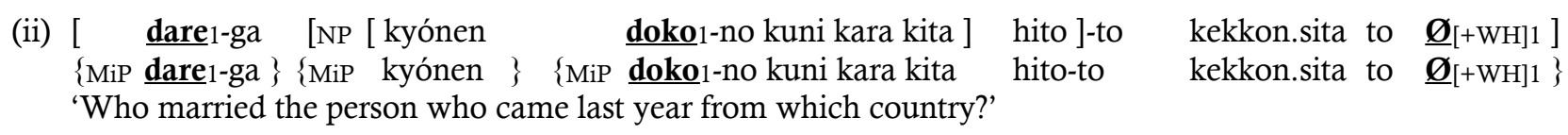

According to Kubo (1990a, p. 104), this is a general pattern; if the second wh element in a multiple wh question is embedded in a relative clause, then in addition to the phrase break and new wh-related minor phrase starting at the second wh element, there is an additional phrase break at the left edge of the "constituent," perhaps the CP, containing that wh element. This fact is of considerable interest, but it is beyond the scope of the present discussion. 
takes priority over WRAP-WH is a constraint that initiates a new minor phrase at each wh element; this can be formalized as Align-L(wh, MiP) (11). The crucial ranking between these two constraints is demonstrated in (12).

(11) Align-L(wh, MiP) The left edge of every wh element is aligned with the left edge of some MiP Violations of this Alignment constraint are assessed categorically (McCarthy 2003)

Align-L(wh, MiP) $>>$ Wrap-WH

\begin{tabular}{|c||c|c|}
\hline [CP doko1 ... nan-nin $\left.1 \ldots \varnothing_{1}\right]$ & Align-L(wh, MiP) & Wrap-WH \\
\hline a. $\left\{\right.$ MiP doko1 ... nan-nin $\left.1 \ldots \varnothing_{1}\right\}$ & $* !$ & \\
\hline b. $\{$ MiP doko $1 \ldots\}\left\{\right.$ MiP nan-nin $\left.1 \ldots \varnothing_{1}\right\}$ & & $*$ \\
\hline
\end{tabular}

The consequence of this ranking is that doko is not phrased with its complementizer (12a) because having a minor-phrase edge at nan-nin (12b) is more important. The constraint WRAP-WH (if it exists at all-see §5) is not ranked high enough to require every wh element to be phrased together with its $\mathrm{C}_{[+\mathrm{WH}]}$ at the expense of Align-L(wh, MiP). In other words, there is no strongly enforced requirement in Fukuoka for every wh element to be phrased with an associated complementizer.

\section{Nested wh questions}

The other configuration that has crucial implications for the wh/C phrasing condition is that of nested wh questions, in which one question is embedded inside another. These cases show that Wrap-C, unlike WrAP-WH, is active in Fukuoka.

Nested wh questions have two wh elements and two complementizers, and one wh/C pair is completely contained within another wh/C pair. In this kind of structure, the entire outer wh...C span is phrased as one large minor phrase (Kubo 1989). Crucially, there is no phrase break at the second wh element, as there is for the multiple wh questions discussed in $§ 3$ (see also Ishihara 2003, 2007 and Kitagawa 2006, 2007 for recent discussion of similar facts in Tokyo Japanese).

(13) Nested wh questions: [CP ... wh1 ... [CP ... wh $\left.\left.\ldots \mathrm{C}_{2}\right] \ldots \mathrm{C}_{1}\right]($ Kubo 1989, p. 3)

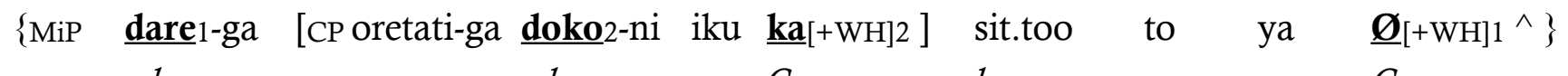
who-NOM we-NOM where-LOC go $C$ know.STAT NZR COP $C$

'Who knows [CP where we are going ] ?'

If Align-L(wh, MiP) >> WRAP-WH were the only relevant constraints, we would expect a new phrase to begin at doko, as seen in (14b), but this is not the case; (14a) is the output that is actually grammatical. 


\begin{tabular}{|c|c|c|c|}
\hline$[\mathrm{CP} \mathrm{C}$ & 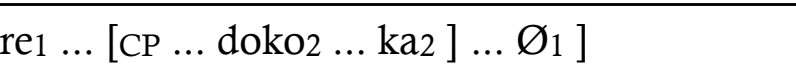 & Align-L(wh, MiP) & WRAP-WH \\
\hline & a. $\left\{\right.$ MiP dare $1 \ldots$ doko $2 \ldots$ ka2 $\left.\ldots \varnothing_{1}\right\}$ & * & \\
\hline * & b. $\{$ Mip dare $1 \ldots\}\left\{\right.$ Mip doko $\left.2 \ldots \mathrm{ka}_{2} \ldots \varnothing_{1}\right\}$ & & * \\
\hline
\end{tabular}

This means that some additional, higher ranked constraint militates against the presence of a phrase break at the embedded wh element in a nested structure such as this one. This cannot be Wrap-WH, which, as has been demonstrated in (12) above, is crucially ranked below Align-L(wh, MiP). This leaves Wrap-C (9a).

Wrap-C > > Align-L(wh, MiP) $>>$ Wrap-WH

\begin{tabular}{|c||c|c|c|}
\hline$\left[\right.$ CP dare $1 \ldots[$ CP doko2 $\ldots$ ka2 $\left.] \ldots \varnothing_{1}\right]$ & WRAP-C & ALIGN-L(wh, MiP) & WRAP-WH \\
\hline a. $\left\{\right.$ MiP dare $1 \ldots$ doko2 $\left.\ldots \mathrm{ka}_{2} \ldots \varnothing_{1}\right\}$ & & $*$ & \\
\hline b. $\{$ MiP dare $1 \ldots\}\left\{\right.$ MiP doko2 $\ldots$ ka2 $\left.\ldots \varnothing_{1}\right\}$ & $* !$ & & $*$ \\
\hline
\end{tabular}

With Wrap-C ranked above Align-L(wh, MiP), starting a new minor phrase at doko (15b) is avoided because the complementizer $\varnothing_{1}$ would be phrased with no associated wh element.

To summarize, the crucial ranking for Fukuoka Japanese is as in (16).

$$
\text { Wrap-C }>>\text { Align-L(wh, MiP) }>>\text { Wrap-WH }
$$

Although not every wh element has to be phrased together with its associated complementizer, as demonstrated by the multiple wh questions in $\S 3$, there is a more stringent requirement, formalized by the constraint WRAP-C, for every [+wh] complementizer to be phrased together with some associated wh element. The effects of WRAP-C emerge when nested wh questions are considered.

\section{Fukuoka wh prosody, the Multiple Spell-Out model, and the syntax-phonology interface}

As noted in the introduction, there are competing approaches to the question of how syntactic structure influences prosodic structure; two leading contenders are the Edge Alignment model (Selkirk 1986; Chen 1987) and the Multiple Spell-Out model (Ishihara 2003, 2007; Kratzer and Selkirk 2007). It is beyond the scope of the current paper to provide a detailed comparison of these two approaches (see Smith 2005a, b for additional discussion). However, a few words about the relationship between the Fukuoka Japanese facts discussed here and the Multiple Spell-Out model are in order, because Multiple Spell-Out provides an account of wh-related prosody in Tokyo Japanese without needing to invoke any wh-specific phrasing conditions at all (Ishihara 2003, 2007). As it turns out, the Fukuoka pattern cannot be reanalyzed in the same way as Tokyo. Thus, Fukuoka still stands as evidence that the syntax-phonology interface is sensitive to wh elements and [+wh] complementizers-as captured by the analysis developed in $\S 3$ and $\S 4$ above-whether or not Multiple Spell-Out is the framework ultimately chosen to model the syntaxphonology interface. 
Like the Fukuoka dialect, Tokyo Japanese also has a characteristic intonational contour in wh constructions, the extent of which is similarly correlated with the span between the wh element and its corresponding complementizer. However, the surface realization of the intonational contour is different from that in Fukuoka. In Tokyo wh questions, the wh element, which bears a pitch accent, is realized with a particularly salient pitch fall. The span between the wh element and its associated complementizer is then realized with a greatly reduced pitch range. This intonational pattern has been shown to be equivalent to the intonation of focus constructions in Tokyo (Deguchi and Kitagawa 2002; Ishihara 2002).

The Multiple Spell-Out model's account of Tokyo wh prosody (Ishihara 2003, 2007) depends on the role of the independently motivated system of focus intonation. In particular, the Multiple Spell-Out approach is only directly able to account for the right edge of the wh-prosody span; the reader is directed to Ishihara's work for detailed discussion, but in brief, whether this span ends at a main-clause complementizer or at an embedded complementizer depends on how much material from the sentence is contained in a single Spell-Out domain, which in turn depends on the scope of the wh element. Crucially, however, the Multiple Spell-Out account does not directly determine the left edge of the wh-prosody span. Instead, it relies on focus phonology to initiate the region of pitch-range reduction at the (focused) wh element.

By contrast, in Fukuoka, wh prosody cannot be reduced to a subcase of focus prosody. As demonstrated instrumentally by Igarashi (2007) and descriptively by Kubo (2010), Fukuoka focus prosody resembles focus prosody in Tokyo quite closely and is therefore strikingly distinct from Fukuoka wh prosody. As a consequence, a mechanism independent of focus phonology is required in order to determine the left edge of the wh-prosody domain in the Fukuoka dialect. In the analysis developed above, that mechanism is the constraint ALIGn-L(wh, MiP). While alternative approaches may also be conceivable, it is clear that some aspect of the syntax-phonology interface must explicitly account for this fact about wh intonation in Fukuoka. Thus, the Multiple Spell-Out model on its own may provide an account of wh prosody in Tokyo, but it is unable to do so for Fukuoka. As a consequence, Fukuoka Japanese is stronger evidence than Tokyo Japanese for the existence of the wh/C phrasing condition and, more generally, for the need to acknowledge that wh elements and complementizers are relevant for the syntax-phonology interface.

\section{Conclusions}

Evidence from multiple wh questions and nested wh questions has shown that the syntax-prosody interface constraint that causes a wh element and its associated complementizer to be phrased together in Fukuoka Japanese is WrAP-C (9a), repeated in (17), not a putative WrAP-WH (9b).

(17) WraP-C Every $\left.\mathrm{C}_{[}+\mathrm{WH}\right]$ must be in the same $\mathrm{PhP}$ as some associated wh element

In fact, the Fukuoka Japanese facts themselves provide no unambiguous evidence that the constraint 
WRAP-WH exists at all ${ }^{9}$ (although cross-linguistic investigation might uncover typological support for this constraint). WRAP-C may be the only WRAP constraint that relates to wh constructions.

In either case-whether WRAP-WH is ranked low, or whether it is entirely absent from the universal constraint set-it is clear that the wh/C phrasing condition in Fukuoka Japanese is a requirement imposed by the complementizer, rather than a requirement imposed by the wh element. The importance of the complementizer in the wh/C phrasing condition can be seen as a prosodic analogue of the principle of 'Enlightened Self-Interest' (Lasnik 1995), which holds that syntactic movement is driven by the requirements of the landing site rather than requirements of the moved element. This additional parallel between syntactic movement and wh-related phonological phrase formation further supports Richards's (2006) fundamental insight that wh prosody and syntactic wh movement are related.

\section{Acknowledgements}

For discussion and comments on this and earlier versions of this project, many thanks to Mary Beckman, Randall Hendrick, Mako Hirotani, Shin Ishihara, Shigeto Kawahara, Tomoyuki Kubo, Elliott Moreton, Lisa Selkirk, Mariko Sugahara, and J. Michael Terry. I am also grateful for the suggestions and comments from an associate editor and three anonymous reviewers.

\section{References}

Chen, M. (1987). The syntax of Xiamen tone sandhi. Phonology Yearbook, 4, 109-149.

Deguchi, M. \& Kitagawa, Y. (2002). Prosody and wh-questions. (In M. Hirotani (Ed.), Proceedings of NELS 32 (pp. 73-92). Amherst: GLSA.)

Hayata, T. (1985). Hakata hougen no akusento • keitairon [The accent and morphology of the Hakata dialect].

(Fukuoka: Kyushu University Press.)

Igarashi, Y. (2007). Pitch accent deletion and pitch range compression in Fukuoka Japanese. (Proceedings of the 21st General Meeting of the Phonetic Society of Japan.)

Inkelas, S. (1989). Prosodic constituency in the lexicon. Dissertation, Stanford University.

Ishihara, S. (2002). Invisible but audible Wh-scope marking: Wh-constructions and deaccenting in Japanese. (In L. Mikkelsen \& C. Potts (Eds.), Proceedings of WCCFL 21 (pp. 180-193). Somerville, Mass.: Cascadilla Press.)

Ishihara, S. (2003). Intonation and interface conditions. Dissertation, MIT.

Ishihara, S. (2007). Major Phrase, Focus Intonation, Multiple Spell-Out (MaP, FI, MSO). The Linguistic Review, 24, $137-167$.

Ito, J. \& Mester, A. (2007). Categories and projections in prosodic structure. (Paper presented at Old World Conference in Phonology 4, Rhodes, Greece.)

Kaisse, E. M. (1985). Connected speech: The interaction of syntax and phonology. (Orlando: Academic Press.)

Kitagawa, Y. (2006). Wh-scope puzzles. (In L. Bateman \& C. Ussery (Eds.), Proceedings of NELS 35, vol. 2 (pp. 335-350). Amherst, MA: GLSA.)

Kitagawa, Y. (2007). When we fail to question in Japanese. (In S. Ishihara (Ed.), Proceedings of the 2nd Workshop on Prosody, Syntax, and Information Structure (WPSI 2). Interdisciplinary Studies on Information Structure, vol. 9 (pp 29-64). Potsdam: University of Potsdam.)

Kratzer, A. \& Selkirk, E. (2007). Phase theory and prosodic spellout: The case of verbs. The Linguistic Review, 24, 93-135.

9 According to the formulation of WRAP constraints by Truckenbrodt (1999), WRAP-WH cannot be the reason why the first wh element in a multiple wh question (10) initiates a wh-related minor phrase, in which pitch accents are deleted (see also (i) in footnote 8). WRAP-WH in tableau (12) is not satisfied, despite the presence of the first wh-related minor phrase, because the wh element is not phrased together with its associated complementizer (see Truckenbrodt 1999: $§ 5.2$ for a case demonstrating the irrelevance of 'partial' satisfaction of WRAP-XP). Thus, while the presence of the non-final wh-related minor phrase in (10) still requires an account, it does not serve as unambiguous evidence for the existence of Wrap-WH. 
Kubo, T. (1989). Hukuoka-si hougen no, dare • nani tou no gimonsi o hukumu bun no pitti pataan [The pitch patterns of sentences containing WH-words in the Fukuoka City dialect]. Kokugogaku, 156, 1-12.

Kubo, T. (1990a). Hukuoka-si hougen no gimonsi hyougen no akusento kisoku [Accent rules for WH expressions in the Fukuoka dialect.] Kyuudai gengogaku kenkyuusitu houkoku, 11, 103-118.

Kubo, T. (1990b). Hukuoka-si hougen no toi-kaesi gimonsi gimonbun (WH-echo) no pitti-pataan [The pitch patterns of WH-echo sentences in the Fukuoka City dialect of Japanese]. Bungaku kenkyuu, 87, 153-179.

Kubo, T. (1992). Hukuoka-si hougen ni okeru akusento syoukyo ni tuite [On accent deletion in Fukuoka-city dialects]. (In T. Kunihiro (Ed.), Nihongo intoneesyon no zittai to bunseki (pp. 265-276). Tokyo: Monbusho.)

Kubo, T. (2001). Hukuoka hougen ni okeru tougoron to on'inron no kyoukai ryouiki [Syntax-phonology interface in the Fukuoka dialect]. Journal of the Phonetic Society of Japan, 5, 27-32.

Kubo, T. (2005). Phonology-syntax interfaces in Busan Korean and Fukuoka Japanese. (In S. Kaji (Ed.), Crosslinguistic studies on tonal phenomena IV (pp. 195-209). Tokyo: ILCAA.)

Kubo, T. (2010). Hukuoka hougen ni okeru dousi • keiyousi to gimonsi-gimonbun no akusento ni kansuru oboegaki [Accent in verbs, adjectives, and WH-questions of the Fukuoka dialect]. Bungaku kenkyuu, 107, 157183.

Lasnik, H. (1995). Case and expletives revisited: On Greed and other human failings. Linguistic Inquiry, 26, 615633.

McCarthy, J. J. (2003). OT constraints are categorical. Phonology, 20, 75-138.

McCawley, J. D. (1968). The phonological component of a grammar of Japanese. (The Hague: Mouton.)

Nagahara, H. (1994). Phonological phrasing in Japanese. Dissertation, UCLA.

Nespor, M. \& Vogel, I. (1986). Prosodic phonology. (Dordrecht: Foris.)

Pierrehumbert, J. B. \& Beckman, M. E. (1988). Japanese tone structure. (Cambridge, MA: MIT Press.)

Poser, W. J. (1984). The phonetics and phonology of tone and intonation in Japanese. Dissertation, MIT.

Richards, N. (2006). Beyond strength and weakness. Ms., MIT. Retrieved March 30, 2008, from http://ling.auf.net/lingBuzz/000325.

Selkirk, E. (1981). On prosodic structure and its relation to syntactic structure. (In T. Fretheim (Ed.), Nordic prosody $I I$ (pp. 111-140). Trondheim: TAPIR.)

Selkirk, E. (1986). On derived domains in sentence phonology. Phonology Yearbook, 3, 371-405.

Selkirk, E. \& Tateishi, K. (1991). Syntax and downstep in Japanese. (In C. Georgopoulos \& R. Ishihara (Eds.), Interdisciplinary approaches to language: Essays in honor of S.-Y. Kuroda (pp. 519-543). Dordrecht: Kluwer.)

Smith, J. L. (2005a). Comments on "Syntax-phonology interfaces in Busan Korean and Fukuoka Japanese" by Tomoyuki Kubo. (In S. Kaji (Ed.), Cross-Linguistic Studies on Tonal Phenomena IV (pp 211-219). Tokyo: ILCAA.)

Smith, J. L. (2005b). On the wh-question intonational domain in Fukuoka Japanese: Some implications for the syntax-prosody interface. (In S. Kawahara (Ed.), Papers on prosody. UMass Occasional Papers in Linguistics (UMOP) 30 (pp. 219-237). Amherst: GLSA. )

Truckenbrodt, H. (1999). On the relation between syntactic phrases and phonological phrases. Linguistic Inquiry, 30, 219-255.

Venditti, J J. (1997). Japanese ToBI labelling guidelines. (In K. Ainsworth-Darnell \& M. D’Imperio (Eds.), Papers from the linguistics laboratory. Ohio State University Working Papers in Linguistics, vol. 50 (pp 127-162). Columbus: The Ohio State University.)

Venditti, J J. (2005). The J_ToBI model of Japanese intonation. (In S.-A. Jun (Ed.), Prosodic typology: The phonology and intonation of phrasing (pp. 172-200). Oxford: Oxford University Press.) 